\title{
A FREQUENTE LUTA DAS MULHERES POR PUNIÇÕES AOS SEUS AGRESSORES: FEMINICÍDIO X LEI MARIA DA PENHA
}

\section{Brizza Oliveira Lima' Amanda Duarte de Souza ${ }^{2}$ Daniel Lipparelli Fernandez ${ }^{3}$}

Resumo: Ainda que existam leis no ordenamento jurídico brasileiro que visam proteger os direitos humanos das mulheres, como a lei $n^{\circ} 11.340$ de 07 de Agosto de 2006 - Lei Maria da Penha, e a mais recente, lei $n^{\circ}$ 13.104 de 09 de março de 2015 - Lei do Feminicídio, que inseriu no $\$ 2^{\circ}$ do artigo 121, do Código Penal a figura do feminicídio como qualificadora do crime de homicídio, perdura ainda, a persistência da violência contra a mulher. Este artigo busca responder a seguinte questão: Se a Lei Maria da Penha fosse mais bem estruturada na sua aplicabilidade, o Feminicídio diminuiria? Com base nas informações coletadas em artigos científicos, pesquisas, leis e em doutrinas do Direito das quais demonstram que a figura do Feminicídio, pode em certas hipóteses imiscuir-se no conhecimento da Lei Maria da Penha, a qual ao ponto de vista deste estudo poderia prevenir diversos feminicídios, preservando a vida de cada uma das mulheres violentadas e muitas vezes mortas.

Palavras-chave: Violência doméstica; Feminicídio; Proteção às vítimas; Punição aos agressores.

\footnotetext{
1 Universidade do Vale do Paraíba - UNIVAP, E-mail: brizzalima@hotmail.com.

2 Universidade do Vale do Paraíba - UNIVAP, E-mail: amandasduarte@outlook.com.

3 Universidade do Vale do Paraíba - UNIVAP, E-mail: fernandez@univap.br.
} 